\title{
Early and late results of pericardiectomy in 118 cases of constrictive pericarditis
}

\author{
V V BASHI, S JOHN, E RAVIKUMAR, P S JAIRAJ, K SHYAMSUNDER, \\ S KRISHNASWAMI \\ From the Department of Thoracic and Cardiovascular Surgery, Christian Medical College and Hospital, \\ Vellore, South India
}

\begin{abstract}
The medical records of 118 patients ( 86 male, 32 female, age 10-50 (mean 27) years) who underwent pericardiectomy for constrictive pericarditis at the Christian Medical College Hospital, Vellore, from 1954 to 1985 were reviewed. All had appreciable pericardial constriction. Preoperatively 97 of the 118 were in class III or IV of the New York Heart Association classification and 100 had peripheral oedema or ascites. Tuberculosis was proved as the cause in 72 patients. Pericardiectomy was accomplished through a standard anterolateral thoracotomy (107 cases), median sternotomy (3 cases), or bilateral thoracotomy (8 cases). Postoperatively an apparent low cardiac output state was seen in 34 patients, 12 of whom died. Hospital mortality in the last 12 years was $11 \%$. Mortality was higher in NYHA class III and IV patients. The improved surgical results recently may be related to increased use of inotropic support and prolonged ventilation. At follow up there were 72 patients in whom functional capacity could be assessed; 63 were in class I or II. The poor results of pericardiectomy in some patients are likely to be related to advanced preoperative disability and early pericardiectomy is therefore recommended.
\end{abstract}

\section{Introduction}

Constrictive pericarditis is the end result of a chronic inflammatory process that produces a fibrosed, thickened, constricted pericardium around the heart with limitation of diastolic ventricular filling. As the encompassing scar shrinks the heart is compressed further, especially the right heart and the great veins.

As early as 1898 DeLorme conceived the idea that pericardial resection for this condition might be feasible, and subsequently Churchill in 1929, Becker in 1930, Harrington in 1940, and Blalock in 1941 reported their experience. The past three decades have brought about improvement in the surgical approach and techniques for pericardial resection. In most patients pericardiectomy corrects the haemodynamic abnormalities and produces dramatic clinical improvement. Considerable controversy continues, however, with regard to the early and late results of the various techniques of pericardiectomy.

Our experience with pericardiectomy at the

Address for reprint requests: Dr Stanley John, Department of Thoracic \& Cardiovascular Surgery, Christian Medical College and Hospital, Vellore 632004 , India.

Accepted 29 April 1988
Christian Medical College and Hospital, Vellore, over 30 years provides the basis for this report.

\section{Patients and methods}

\section{PATIENTS}

The medical records of all patients undergoing pericardiectomy for constrictive pericarditis at this institution from January 1954 to December 1985 were reviewed. Only patients with clinical, operative, and pathological features of pericarditis and constriction were included. Patients with purulent pericarditis or recurrent pericarditis without constriction were excluded. A total of 118 patients met these criteria and the study represents a review of their clinical features, invasive and non-invasive preoperative investigations, early postoperative course, and long term results.

Ages ranged from 10 to 50 (mean 27 (SD 11.5) years) (table 1). The disease was most prevalent in the age range 11-40 years and less prevalent in the very young and old. There was a male preponderance with a male: female ratio of $2 \cdot 7: 1$. The duration of the symptoms varied from one to 15 (mean 6) years. Our patients were referred from different hospitals and before referral many were extensively investigated and treated for various suspected hepatic, malignant, and cardiac disorders. 
Table 1 Age distribution and sex ratio of the patients

\begin{tabular}{lc}
\hline Age $(y)$ & No of cases \\
\hline $1-10$ & 4 \\
$11-20$ & 31 \\
$21-30$ & 43 \\
$31-40$ & 26 \\
$41-50$ & 8 \\
$51-60$ & 6 \\
Sex ratio (M:F) & $3 \cdot 7: 1$ \\
\hline
\end{tabular}

Preoperative disability was categorised according to the New York Heart Association classification. At the time of diagnosis two patients $(1.7 \%)$ were class $I, 19$ $(6 \%)$ class II, $57(48 \%)$ class III, and $40(34 \%)$ class IV. All patients had clinical evidence of pericardial constriction; the common physical findings that were striking were raised jugular venous pressure in all 118, peripheral oedema in $99(84 \%)$, ascites in $106(90 \%)$, hepatomegaly in all 118 , splenomegaly in $21(18 \%)$, pleural effusion in $64(54 \%)$, muffled heart sounds in $116(98 \%)$, and pulsus paradoxus in $99(84 \%)$.

Results of various preoperative investigations are summarised in table 2. Radiological evidence of pericardial calcification was present in 25 cases (fig 1) and pleural effusion in 63. Cardiac catheterisation and angiocardiography were performed in 84 patients and were diagnostic of a constrictive or restrictive process in all. A characteristic dip and plateau pattern was seen in the right ventricular wave forms with equalisation of end diastolic pressures in all four cardiac chambers and pulmonary artery (fig 2). A ratio of systolic to end diastolic pressure of less than 3:1 was seen in all patients. The mean (SD) values of the preoperative intracardiac pressures were as follows: right atrium (mean) $18(5) \mathrm{mm} \mathrm{Hg}$, right ventricle (end diastolic) 20 (6) mm Hg, pulmonary artery (diastolic) 21 (7) $\mathrm{mm} \mathrm{Hg}$, left atrium (mean) 21 (5) $\mathrm{mm} \mathrm{Hg}$, left ventricle (end diastolic) 21 (5) $\mathrm{mm} \mathrm{Hg}$. The mean (SD) cardiac index was $1.8(0.6) \mathrm{l} / \mathrm{min} / \mathrm{m}^{2}$

On the basis of the clinical data and operative and pathological findings we were able to identify a specific aetiological factor, tuberculosis, in $72(61 \%)$ of the 118

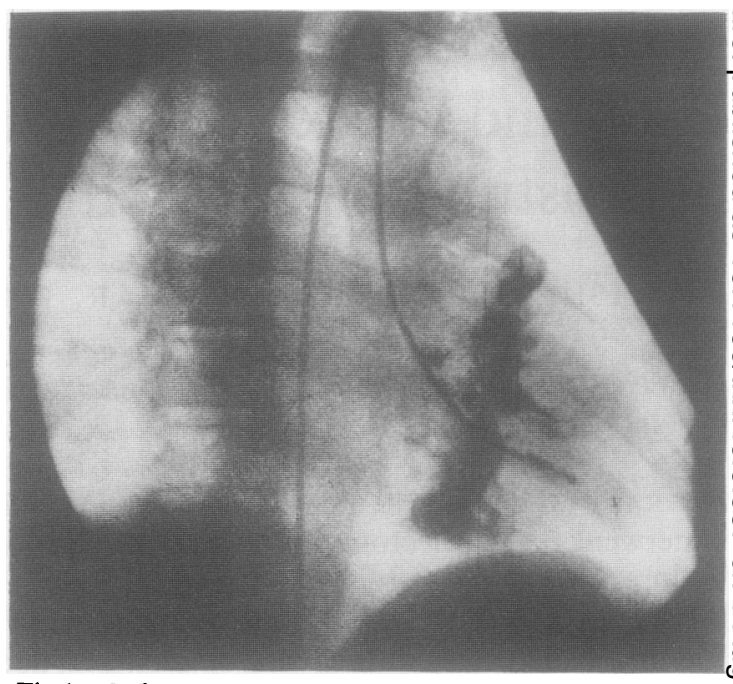

Fig 1 Left anterior oblique view showing dense calcification in the pericardium at the atrioventricular groove and $a$ catheter in position for angiography.

patients. In a few cases tubercle bacilli were found in the fluid and debris removed at surgery. In about $12 \stackrel{\bar{\partial}}{\circ}$ cases in the tuberculous group we found an effusive constrictive pericarditis. ' Two patients in the non- $\mathbb{\mathbb { D }}$ specific group also had mitral stenosis and a past $\overrightarrow{\vec{P}}$ history of rheumatic fever.

\section{OPERATIVE PROCEDURE}

Pericardiectomy was performed through a standard left anterolateral thoracotomy through the 4th or 5th o intercostal space with provision for transecting the $\stackrel{\otimes}{\times}$ sternum when necessary. Early in our experience a $\frac{0}{3}$ bilateral submammary thoracotomy was used in eight patients. ${ }^{2}$ Median sternotomy was carried out only in $ᄋ$ three cases, where there was extensive calcification of $₹$ the pericardium. Cardiopulmonary bypass was not 을 used for any patient. The process of decortication was $\supset$ generally terminated on the left side as soon as the left atrioventricular groove was reached after mobilisation $N$ and retraction of the left phrenic nerve. On the right ${ }^{\circ}$

Table 2 Results of preoperative investigations

\begin{tabular}{|c|c|c|c|c|}
\hline \multirow[b]{2}{*}{ Investigation } & \multirow{2}{*}{$\begin{array}{l}\text { No of } \\
\text { patients }\end{array}$} & \multirow[b]{2}{*}{ Abnormality detected } & \multicolumn{2}{|c|}{ Positive } \\
\hline & & & No & $\%$ \\
\hline Chest radiograph & 118 & $\begin{array}{l}\text { Pericardial calcification } \\
\text { Pleural effusion } \\
\text { Cardiomegaly }\end{array}$ & $\begin{array}{l}25 \\
63 \\
70\end{array}$ & $\begin{array}{l}21 \\
53 \\
59\end{array}$ \\
\hline Electrocardiograph & 118 & $\begin{array}{l}\text { Low voltage QRS complex } \\
\text { Atrial arrhythmias }\end{array}$ & $\begin{array}{r}89 \\
9\end{array}$ & $\begin{array}{l}75 \\
10\end{array}$ \\
\hline $\begin{array}{l}\text { Fluoroscopy } \\
\text { Echocardiography } \\
\text { Cardiac catheterisation }\end{array}$ & $\begin{array}{l}60 \\
78 \\
84\end{array}$ & $\begin{array}{l}\text { Evidence of restriction } \\
\text { Pericardial thickening } \\
\text { Increase in end diastolic pressures }\end{array}$ & $\begin{array}{l}42 \\
33 \\
84\end{array}$ & $\begin{array}{r}70 \\
42 \\
100\end{array}$ \\
\hline
\end{tabular}




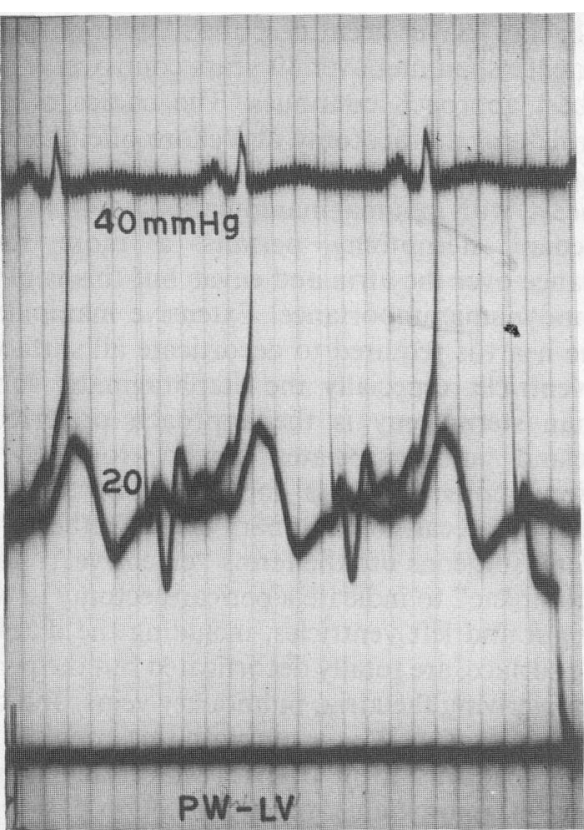

Fig 2 Pulmonary wedge ( $P W$ ) and left ventricular ( $L V)$ pressure curves depicting the classical equalisation of end diastolic pressures.

side the decortication was limited to the right atrioventricular groove. Partial pericardiectomy has been shown both haemodynamically and clinically to be adequate. The extent of further resection of the pericardium overlying the atria or the intrapericardial portion of the cavae and pulmonary veins depends on the adequacy of the exposure and the need for it. In only two instances, where a gradient of 6-8 $\mathrm{mm} \mathrm{Hg}$ had been documented by preoperative catheterisation, was decortication accomplished at the cavoatrial junction. Our impression is that constriction of the cavae and pulmonary veins is rarely evident. Particular attention was directed to the excision of constricting epicardial layers. We had no hesitation in leaving islands of calcified pericardium infiltrating the myocardium.

\section{Results}

\section{EARLY POSTOPERATIVE RESULTS}

Nineteen patients died within 30 days of surgery, giving a hospital mortality of $16 \%$. In the last 12 years, however, only six of 52 patients $(11 \%)$ died in hospital. The causes of death were an apparent low cardiac output state (12), bleeding from the great vessels after laceration (3), respiratory failure (1), and cardiac arrhythmias (3). In the patients with an apparent low cardiac output the poor cardiac performance was not the result of unrelieved constriction.
Table 3 Postoperative complications

\begin{tabular}{lrr}
\hline Complication & No & $\%$ \\
\hline Atrial fibrillation & 39 & 33 \\
Premature ventricular contractions & 6 & 5 \\
Low cardiac output & 34 & 28 \\
Respiratory insufficiency & 25 & 21 \\
\hline
\end{tabular}

Not infrequently the surgeon noticed minimal dilatation of the heart during pericardiectomy. Low cardiac output was diagnosed when hypotension, cold extremities, a weak pulse, and oliguria were evident, and varying degrees were observed in the early postoperative period in 34 patients (table 3), even though a satisfactory pericardiectomy had been carried out. An appreciable number of these patients required inotropic support with dopamine to improve cardiac function, and some required ventilatory assistance.

Among the 21 patients who were in functional class I and II (NYHA) before operation, there was only one operative death, whereas among the 97 in classes III and IV there were 18 deaths $(18 \cdot 6 \%)$.

The operative mortality was analysed from 1954 to 1973 and from 1974 to 1986 . There was a favourable decline in the operative mortality from $16 \%$ during $1954-73$ to $11 \%$ during $1974-86$, possibly related to improvements in perioperative care. During the latter period patients were in more advanced stages of the disease.

Preoperative chest radiographs and electrocardiograms were available for all patients. There was no significant difference in operative mortality relating to pericardial calcification on the chest radiograph or to low voltage $Q R S$ complex or atrial arrhythmias in the preoperative electrocardiogram $(\mathrm{p}>0.05)$.

\section{FOLLOW UP}

Of the 99 survivors, 78 were followed from periods ranging from two to 30 (mean 9 (SD 6.5) years. Patients with this disease often belong to a low socioeconomic group, and once symptom free they failed to report for follow up. Of the 78 patients who have been followed, most are in good or excellent condition. None required reoperation for recurrent constriction. Of the 72 subjects in whom functional capacity could be assessed, 59 were in functional class I, four in class II, and nine in class III (NYHA). There were six late deaths. The cause was unrelated to pericarditis in four patients, but two died of progressive cardiac failure.

\section{Discussion}

Although the constrictive effect of chronic pericarditis affects all four cardiac chambers and the intrapericar- 
dial portions of the cavae and pulmonary veins, the only important haemodynamic abnormality that is consistent is impairment of ventricular diastolic filling. ${ }^{3-9}$ There is an apparent encasement of the ventricles with impaired systole as a result of myocardial lesions. These two factors offer a plausible explanation for the low stroke volume, pleural effusion, ascites, oedema, and engorged neck veins. Several patients showed altered liver function, some with a protein losing enteropathy as described. ${ }^{10}$ The diagnosis is frequently overlooked for many years, early clinical findings being subtle and the specificity of the common non-invasive tests low. ${ }^{311} 1213$

Tuberculosis is the leading cause of constrictive pericarditis in the Third World and in our study 72 patients $(61 \%)$ had proved tuberculosis according to histopathological findings. Two patients also had mitral stenosis and a past history of rheumatic fever. McCoughan and colleagues ${ }^{14}$ were able to identify a specific aetiological factor in only $27 \%$ of their patients and Blake and colleagues ${ }^{15}$ in only $34 \%$. In the very early report from Massachusetts General Hospital tuberculosis was the proved cause in only $17 \%{ }^{16}$ Tuberculosis remains a major cause of constrictive pericarditis in Third World countries where pulmonary tuberculosis remains endemic. ${ }^{12}{ }^{17-19}$ Non-infective processes leading to a pericardial inflammatory response include irradiation, ${ }^{20-22}$ haemopericardium, ${ }^{11} 1323$ collagen diseases, ${ }^{1124-26}$ and metabolic infiltration. ${ }^{27}$ Cardiac surgery has also been implicated; the incidence of constrictive pericarditis after cardiac surgery is reported to be around $0 \cdot 15 \% .{ }^{2829} 30$

The striking male to female ratio of $2 \cdot 7: 1$ in this study is at variance with the ratio of $1: 3$ reported by Wood $^{31}$ and 1:1 reported by Gupta. ${ }^{32}$ The disease occurred most frequently in the second, third, and fourth decades of life in our series, as noted by Levine. ${ }^{33}$ The presence of ascites without oedema may lead to an erroneous diagnosis of abdominal tuberculosis, ${ }^{31}$ though in most of our patients ascites was associated with peripheral oedema. We assume that ascites and peripheral oedema are in great measure the result of the protein losing enteropathy. The high incidence of cardiac arrhythmias reported by Wood was not seen in our series, perhaps because our patients were younger.

Contrary to the belief that the cardiac shadow on the chest radiograph in constrictive pericarditis is either normal or slightly enlarged, ${ }^{34}$ we found that it was definitely enlarged in half of our patients. Low voltage $Q R S$ complexes with typical $T$ wave changes were found on the electrocardiograph of most of our patients.

In 1928 Churchill $^{35}$ performed the first successful pericardiectomy for constrictive pericarditis. Subsequently several different operative techniques and approaches have been described. ${ }^{3411-132936}$ Despite $\overrightarrow{\vec{F}}$ experience spanning over 30 years controversy about the best approach continues. The choice of a left anterolateral thoracotomy at Vellore offers excellent $\frac{\bar{F}}{\bar{n}}$ exposure of the anterolateral and inferior surface of $\vec{\nabla}$ the heart, with minimal manipulation.

Median sternotomy permits a more radical is clearance over the atria and cavae but this is of little $\overrightarrow{0}$ haemodynamic importance. Extensive manipulation of the heart is required to decorticate all surfaces of $\vec{\omega}$ left ventricle, especially the diaphragmatic surface. Median sternotomy is the approach preferred by $x$ Copeland and associates, ${ }^{36}$ who routinely use $\vec{\omega}$ cardiopulmonary bypass for pericardiectomy. We have not used cardiopulmonary bypass hitherto. के

Many surgeons use the terms "extensive", "total," or "complete" to indicate a pericardiectomy in which $\stackrel{5}{工}$ the right and left ventricles, including the diaphrag- $\vec{D}$ matic surface, are totally decorticated but the pericardium overlying the atria, pulmonary veins, and cavae $\frac{c}{\infty}$ is left in place. ${ }^{11-13}$ We concur with this approach and believe that this form of pericardiectomy achieves $\emptyset_{\infty}$ optimal haemodynamic relief. Resection of adherent $\infty$ pericardium over the atria is considered hazardous; in the earlier part of our study, when decortication was extended to these areas, laceration of the inferior cavae

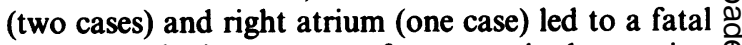
outcome. The importance of unrecognised constrict- $\stackrel{\mathbb{Q}}{\unrhd}$ ing epicardial peel has been described by Harrington ${ }^{4} \overrightarrow{\overrightarrow{2}}$ and recently by Walsh and associates. ${ }^{37}$ Wherever this $\frac{\circ}{3}$ constricting peel was very adherent and calcified we had no hesitation in leaving islands of pericardium, after making multiple incisions, to avoid injury to major coronary vessels.

The hospital mortality after pericardiectomy for $\stackrel{\curvearrowright}{\times}$ chronic constrictive pericarditis remains at 5-15\%. In $\frac{0}{7}$ our series hospital mortality bore a strong relation to preoperative functional state. Our mortality in the last 12 years $(11 \%)$ is similar to that in other reports. ${ }^{14}$

Consistently good late results have been reported 욱 in many large series of patients undergoing pericar- $>$ diectomy for constrictive pericarditis and our experience is similar. From our own experience and a No review of published reports it is evident that a fewpatients develop a low cardiac output state after pericardiectomy regardless of the operative approach $w$ and the adequacy of pericardial resection. Operative, clinical, haemodynamic, and necropsy findingse indicate that impaired cardiac performance is usually $\mathbb{D}$ secondary to myocardial dysfunction rather than ? unrelieved constriction. ${ }^{68202738}$ The most common 70 cause of myocardial dysfunction is myocardial atro- $\frac{}{\mathbb{D}}$

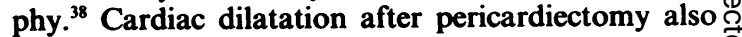
gives rise to a low cardiac output syndrome post- $\stackrel{\mathbb{Q}}{\complement}$ operatively. The results of radical pericardiectomy have been good $^{3}$ but whether this will prevent cardiac 
dilatation from poor myocardial function postoperatively is doubtful. Surgical results will continue to improve if the diagnosis is established and pericardiectomy accomplished before pronounced disability ensues.

We gratefully acknowledge the statistical help of Mr K Mani and the secretarial assistance of Mr R Mohanavelu.

\section{References}

1 Hancock EW. Subacute effusive-constrictive pericarditis. Circulation 1971;43:183-92.

2 Sukumar IP, Vytilingam KI, McPhail JS, John S. Results of surgery in constrictive pericarditis with pre and postoperative haemodynamic assessment. Indian Heart J 1966;18:213-8.

3 Culliford AT, Lipton M, Spencer FC. Operation for chronic constrictive pericarditis. Do the surgical approach and degree of pericardial resection influence the outcome significantly? Ann Thorac Surg 1980;29:146-52.

4 Harrington SW. Chronic constrictive pericarditis: partial pericardiectomy and epicardiolysis in twenty-four cases. Ann Surg 1944;120:468-87.

5 Shalutai R, Fowler NO, Guthevoth WG. The haemodynamics of cardiac tamponade and constrictive pericarditis. Am J Cardiol 1970;26:480-6.

6 Harrison EC, Crawford DW, Lau FY. Sequential left ventricular function studies before and after pericardiectomy for constrictive pericarditis. Delayed resolution of residual restriction. $\mathrm{Am} J$ Cardiol 1970;26:319-23.

7 Viola AR. The influence of pericardiectomy on the haemodynamics of chronic constrictive pericarditis. Circulation 1973;48:1038-42.

8 Ghose JC, Saha P, Burdhan A, Chhetri MK. Left ventricular function in chronic constrictive pericarditis before and after pericardiectomy. J Assoc Physn India 1977;25:851-7.

9 Das PB, Krishnaswami S, John S. Myocardial function and its effect on the surgical treatment of constrictive pericarditis. Indian Heart $J$ 1975;27:127-31.

10 Peterson VP, Hastrup J. Protein-losing enteropathy in constrictive pericarditis. Acta Med Scand 1963; 173:401-10.

11 Wychullis AR, Connolly DC, McGoon DC. Pericardial cysts, tumors and fat necrosis. $J$ Thorac Cardiovasc Surg 1971;62:294-300.

12 Das PB, Gupta RP, Jairaj PS, et al. Constrictive pericarditis and its surgical management. Int Surg 1975;60:210-4.

13 Kilman JW, Bush CA, Wooley CF, Stang JM, Teply J, Baba N. The changing spectrum of pericardiectomy for chronic pericarditis. Occult constrictive pericarditis. J Thorac Cardiovasc Surg 1977;74:668-73.

14 McCaughan BC, Schaff HV, Piehler JM, et al. Early and late results of pericardiectomy for constrictive pericarditis. J Thorac Cardiovasc Surg 1985;39:340-50.
15 Blake S, Bonar S, O'Neill H, et al. Aetiology of chronic constrictive pericarditis. Br Heart J 1983;50:273-6.

16 Paul O, Castleman B, White PD. Chronic constrictive pericarditis. A study of 53 cases. Am J Med Sci 1948;216:361-77.

17 Gooi HC, Smith JM. Tuberculous pericarditis in Birmingham. Thorax 1978;33:94-6.

18 Ortbals DW, Avioli LV. Tuberculous pericarditis. Arch Intern Med 1979;139:231-4.

19 Desai HN. Tuberculous pericarditis. A review of 100 cases. S Afr Med J 1979;55:877-80.

20 Applefeld MM, Slawson RG, Hall-Craigs M, et al. Delayed pericardial disease after radiotherapy. Am J Cardiol 1981;47:210-3.

21 Watson PT, Havelda CJ, Sorosky J, et al. Irradiationinduced constrictive pericarditis requiring pericardiectomy during pregnancy. $J$ Reprod Med 1980;24:127-30.

22 Martin RG, Ruckdeschel JC, Chang P, et al. Radiationrelated pericarditis. Am J Cardiol 1975;35:216-20.

23 Ehrenaft JL, Taber RE. Haemopericardium and constrictive pericarditis. $J$ Thorac Surg 1952;24:355-68.

24 Cooper DK, Cleland WP, Bentall HH. Collagen diseases as a cause of constrictive pericarditis. Thorax 1978;33:368-71.

25 John JT Jr, Hough A, Sergent JS. Pericardial disease in rheumatoid arthritis. Am J Med 1979;66:385-90.

26 Sunder SK, Shah A. Constrictive pericarditis in procainamide induced lupus erythematosus syndrome. $\mathrm{Am} J$ Cardiol 1975;36:960-2.

27 Meaney E, Shabetai R, Bhargava V, et al. Cardiac amyloidosis, constrictive pericarditis and restrictive cardiomyopathy. Am J Cardiol 1976;38:547-56.

28 Kutcher MA, King SB 3d, Alimurung BN, et al. Constrictive pericarditis as a complication of cardiac surgery. Recognition of an entity. Am J Cardiol 1982;50:742-8.

29 Miller JI, Mansour KA, Hatcher CR Jr. Pericardiectomy: current indications, concepts and results in a university center. Ann Thorac Surg 1982;34:40-5.

30 Marsa R, Mehta S, Willis W, Bailey L. Constrictive pericarditis after myocardial revascularisation. Report of three cases. Am J Cardiol 1979;44:177-83.

31 Wood P. Chronic constrictive pericarditis. Am J Cardiol 1961;7:48-61.

32 Gupta RL. Pericardiectomy in constrictive pericarditis. Indian Heart $J$ 1971;23:292-5.

33 Levine SA. Clinical heart disease 5th ed. Philadelphia: Saunders, 1958.

34 Baue AE, et al. The pericardium. Ann Thorac Surg 1972;14:81-106.

35 Churchill ED. Decortication of the heart (Delorme) for adhesive pericarditis. Arch Surg 1929;19:1457-67.

36 Copeland JG, Stinson EB, Griepp RB, et al. Surgical treatment of chronic constrictive pericarditis using cardiopulmonary bypass. $J$ Thorac Cardiovasc Surg 1975;69:236-8.

37 Walsh TJ, Baughman KL, Gardner TJ, Bulkley BH. Constrictive epicarditis as a cause of delayed or absent response to pericardiectomy: a clinicopathological study. J Thorac Cardiovasc Surg 1982;83:126-32.

38 Dines DE, Edwards JE, Burchell WB. Myocardial atrophy in constrictive pericarditis. Mayo Clinic Proc 1958;33:93-9. 